\title{
Oxidosqualene Cyclase (OSC) Inhibitors for the Treatment of Dyslipidemia
}

\author{
Henrietta Dehmlowa§^, Jean Ackermannn ${ }^{\mathrm{a}}$, Johannes Aebia , Denise Blum-Kaelina, \\ Alexander Chucholowski ${ }^{b}$, Philippe Coassolo ${ }^{a}$, Peter Hartman ${ }^{\mathrm{a}}$, Manfred Kansya ${ }^{\mathrm{a}}$, \\ Hans Peter Märki ${ }^{a}$, Olivier Morand ${ }^{\mathrm{c}}$, Elisabeth Von der Mark ${ }^{\mathrm{a}}$, Narendra Pandaya ${ }^{\mathrm{a}}$, Armin Rufa, \\ Ralf Thoma ${ }^{\mathrm{a}}$, and Tanja Schulz-Gascha \\ $\S$ Mettler Toledo Award Winner (Oral Presentation)
}

\begin{abstract}
Novel inhibitors of oxidosqualene cyclase (OSC) for the treatment of dyslipidemia are reported. Starting point for the chemistry program was a set of compounds derived from a fungicide project which, in addition to high affinity for OSC from Candida albicans, also showed high affinity for the human enzyme ( $h \mathrm{OSC}$ ). Here the evaluation process of different scaffolds is outlined for two representative series, the phenyl substituted benzo[d]isothiazoles and the aminocyclohexanes. The most promising compounds derived from the latter series were further profiled in vivo and showed promising properties with respect to modulation of lipid parameters.
\end{abstract}

Keywords: Dyslipidemia $\cdot$ Medicinal chemistry $\cdot$ Oxidosqualene cyclase $\cdot$ Structure-activity relationship

\section{Introduction}

One of the most common cases of death in the western world is artherosclerotic cardiovascular disease, accounting for over $30 \%$ of deaths [1]. In epidemiological and prospective studies several risk factors have been identified which promote the development of atherosclerosis [2-5]. These include, in addition to life habit risk factors such as obesity, smoking and physical inactivity, elevated plasma levels of low-density lipoprotein cholesterol (LDL-C), low plasma high-density lipoprotein cholesterol (HDL-C), and elevated concentrations of plasma triglyceride (TG)-rich lipoproteins. A strong correlation for the occurrence of coronary heart disease (CHD) cases with LDL-C and TG levels in plasma has been

\footnotetext{
${ }^{\star}$ Correspondence: Dr. H. Dehmlowa ${ }^{a}$

Tel.: + 41616889040

Fax: + 41616889748

E-Mail: henrietta.dehmlow@roche.com

apharma Division

Preclinical Research

F. Hoffmann-La Roche Ltd

CH-4070 Basel

${ }^{b}$ ChemBridge Research Laboratories, LLC (CRL)

16981 Via Tazon

San Diego, CA 92127, USA

cActelion Pharmaceuticals Ltd

Gewerbestrasse 16

$\mathrm{CH}-4123$ Allschwil
}

observed [2][6], and the clinical benefit associated with the lowering of LDL-C levels is now well established for both primary as well as secondary prevention [2][7][8].

Current standard therapies for the pharmacologic treatment of lipid abnormalities effectively modulate only one of the lipid parameters. So the most widely used lipid-modifying drugs, statins (3-hydroxy-3methyl gluturyl coenzyme A (HMG-Co-A) reductase inhibitors) very effectively reduce plasma LDL-C by $30-45 \%$ at standard dose while affecting the plasma triglyceride level to a lesser extent. On the other hand, fibrates (fibrate ester derivatives) reduce plasma levels of triglycerides more effectively, but not LDL-C levels. Although statins are well tolerated at standard doses and adverse events are rare, side effects reported at high doses are elevated liver enzyme levels, myopathy and rhabdomyolisis.

In this context 2,3-oxidosqualene:lanosterol cyclase (OSC; E.C. 5.4.99.7) inhibition, which would allow a concomitant lowering of both LDL-C and TG levels, was identified as a potential target to improve current therapies [9]. OSC, a microsomal membrane-associated enzyme consisting of 732 aa with a size of $83.4 \mathrm{kDa}$, is located down-stream of HMG-CoA reductase in the biosynthetic pathway of cholesterol. It catalyzes the selective cyclization of the linear substrate 2,3-oxidosqualene (mono-oxidosqualene, MOS) to lanosterol [10][11]. Inhibition of OSC, in contrast to
HMG-CoA reductase inhibition, should not lead to an undesired reduction of isoprenoid intermediates of cholesterol synthesis and their metabolites, e.g. coenzyme Q10 [9]. Furthermore, OSC inhibition has an indirect, negative feed-back regulatory mechanism [12] involving 24(S),25-epoxycholesterol which potentiates the primary inhibitory effect and reduces the accumulation of mono-oxidosqualene in the liver. In addition, potential OSC inhibitors could also indirectly activate liver $\mathrm{X}$ receptor (LXR) dependent pathways via 24(S),25-epoxycholesterol, a known potent natural agonist of the nuclear receptor LXR [13][14].

\section{Starting Point and Strategy}

A set of compounds derived from a fungicide project [15][16] which in addition to high affinity for OSC from Candida albicans, also showed high affinity for $h \mathrm{OSC}$ [9][17] served as a starting point for the chemistry program. Common structural features of all of these inhibitors are an amine residue and an electrophilic carbonyl-Catom embedded in a benzophenone system. As neither an X-ray structure of hOSC [18] nor of related enzymes such as the prokaryotic counterpart of OSC squalene hopene cyclase (SHC) [19][20] were known at the start of the project, the optimization process was guided by a pharmacophore model. This model was derived by superimposing 
the structure of the folded, high energy conformer of mono-oxidosqualene (mimicking an opened protosterol) and 1 (Ro 48-8071) as depicted in Fig. 1b. Later analysis of the $\mathrm{X}$-ray of $\mathbf{1}$ in complex with $h \mathrm{OSC}$ supported this initial model. The essential interactions of 1 with the protein are depicted in Fig. 1c and 1d. The hydrogen bond between the nitrogen of the N,N-methylallylamine moiety and the carboxylate of the catalytic acid Asp 455 demonstrates the importance of the basic amine residue of the inhibitors. The electron-deficient aromatic part of the benzophenone system is embedded in a pocket formed by Phe 521 and His 232. Furthermore, the carbonyl moiety of the benzophenone indirectly interacts with Ile338 via a water molecule.

The goal of the optimization was to identify $h$ OSC inhibitors with increased potency both in vitro and in vivo, increased metabolic stability and higher drug exposure in the target organs as compared to $\mathbf{1}$. As the carbonyl moiety of the benzophenone residue was considered a potential site of metabolism [21] one approach consisted of replacing the benzophenone by other core structures. Several alternative core structures including heterocyclic derivatives such as phenyl substituted benzo[d]isothiazoles, benzisoxazoles, dioxo-benzo[d]isothiazole, benzo[b]thiophenes, indazoles, isoxazoles and indoles as well as substituted indolines, piperidines, anilines and aminocyclohexanes were explored [17][22]. For most core scaffolds rapid evaluation of different spacers and amine substituents was possible by parallel synthesis. The process is depicted for two representative classes, the substituted benzo[d]isothiazoles and aminocyclohexane derivatives.

\section{Chemistry}

The synthesis for benzo[d]isothiazoles is outlined in Scheme 1 [17]. Starting from 3-fluoro-anisole (2), Friedel-Crafts acylation with 4-bromo benzoyl chloride (3) in the presence of $\mathrm{AlCl}_{3}$ gave the desired benzophenone 4 . Reaction of $\mathbf{4}$ with benzylmercaptane in the presence of potassium $t$-butylate yielded the thioether derivative 5 which upon treatment with sulfuryl chloride and ammonia gave benzo[d]isothiazole (6) [23]. Subsequent cleavage of the methylether with boron tribromide gave phenol 7, which was subjected to alkylation with an excess of $\alpha, \omega$-dibromoalkanes to yield the intermediates $\mathbf{8}$ that were converted to the final amines 9 by reaction with different primary or secondary amines.

Furthermore, intermediates $\mathbf{8}$ could be oxidized with $\mathrm{KMnO}_{4}$ to give the bromo-

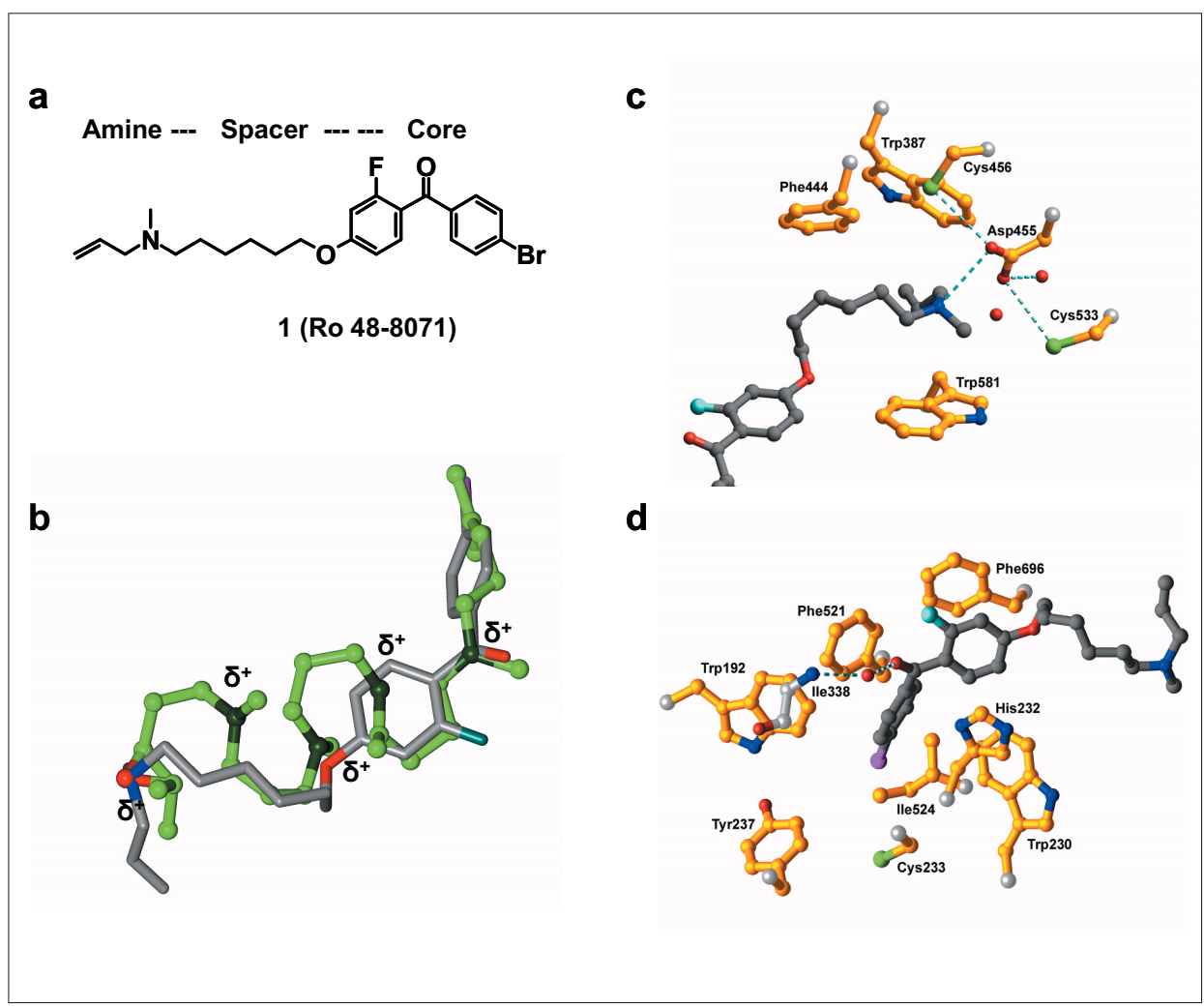

Fig. 1. a) 1 Ro 48-8071; b) Superimposed structures of the folded, high energy conformer of oxidosqualene (mimicking the opened protosterol) and 1 (Ro 48-8071); c) Binding interactions with the amine residue; d) Binding interactions with the benzophenone moiety

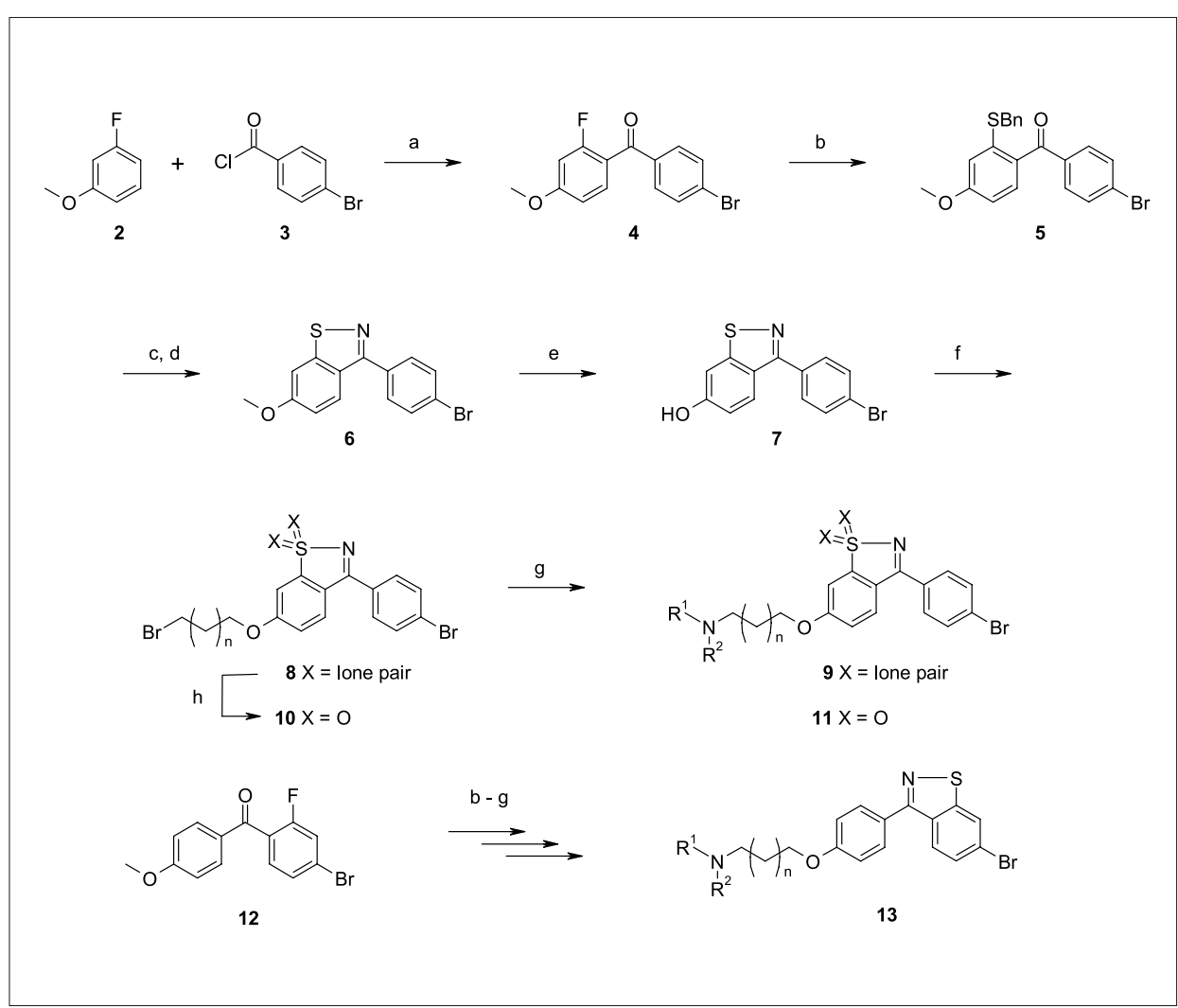

Scheme 1. Synthesis of heteroaromatic compounds - benzo[d]isothiazole derivatives. Reagents and conditions: a) $\mathrm{AlCl}_{3}, \mathrm{PhNO}_{2}, \mathrm{O}^{\circ} \mathrm{C}$ to rt, $42 \%$; b) $\mathrm{KOt}$-Bu, BnSH, THF, rt; c) $\mathrm{SO}_{2} \mathrm{Cl}_{2}, \mathrm{CH}_{2} \mathrm{Cl}_{2}, \mathrm{rt}$ d) $\mathrm{NH}_{3}$, $\mathrm{EtOH}$, rt; e) $\mathrm{BBr}_{3}, \mathrm{CH}_{2} \mathrm{Cl}_{2},-78{ }^{\circ} \mathrm{C}$ to rt, $73 \%$ (from 4); f) $\alpha, \omega$-dibromoalkane, $10 \%$ aq. $\mathrm{NaOH}, \mathrm{N}(\mathrm{Bu})_{4} \mathrm{Br}$, $\mathrm{CH}_{2} \mathrm{Cl}_{2}, \mathrm{rt}, 70 \%$; g) $\mathrm{NHR}^{1} \mathrm{R}^{2}$, DMA, rt, 70-88\%; (h) $\mathrm{KMnO}_{4} / \mathrm{SiO}_{2}, \mathrm{CH}_{2} \mathrm{Cl}_{2}, \mathrm{rt}, 80 \%$. 
alkyloxy dioxo-benzo[d]isothiazoles $\mathbf{1 0}$ which were further converted to the final products 11 by amination. Analogous to compounds 9, the benzo[d]isothiazoles $\mathbf{1 3}$ were derived from benzophenone $\mathbf{1 2}$.

For the aminocyclohexane derivatives with oxygen-linked spacers the synthesis is depicted in Scheme 2. The synthesis started from trans-4-aminocyclohexanol (14) which was converted to the BOC-protected trans-4-methylaminocyclohexanol (15) by treatment with $\mathrm{ZCl}$, reduction with $\mathrm{LAH}$ followed by BOC-protection. 15 was alkylated under phase transfer conditions with $\alpha, \omega$-dihaloalkanes to yield the bromide $\mathbf{1 6}$. Alternatively, 15 was treated with $\alpha, \omega$-dihaloalkanes in the presence of $\mathrm{NaH}$ in DMF or especially for shorter spacer lengths with the in situ generated haloalkane-triflates (from the corresponding haloalkanols with trifluoromethansulfonic anhydride/2,6di-tert-butylpyridine [24]). The reaction of bromide 16 with primary or secondary amines followed by cleavage of the BOC protecting group gave the intermediate $\mathbf{1 7}$ as TFA salt. 17 was converted to different sulfonamides 18 or carbamates $\mathbf{1 9}$ by reaction with sulfonyl chlorides or chloroformates, respectively. In a similar manner urea, sulfamide, amide, thiourea or thioamide analogues were prepared (not shown).

Analogous aminocyclohexanes with carbon-linked spacers were prepared as depicted in Scheme 3 for compounds with a pentyl spacer. The synthesis started from (trans)-4-t-butoxycarbonyl amino-cyclohexane-carboxylic acid (20) which was converted to its ester prior to $\mathrm{N}$-alkylation using $\mathrm{NaH}$ and methyl iodide. Reduction

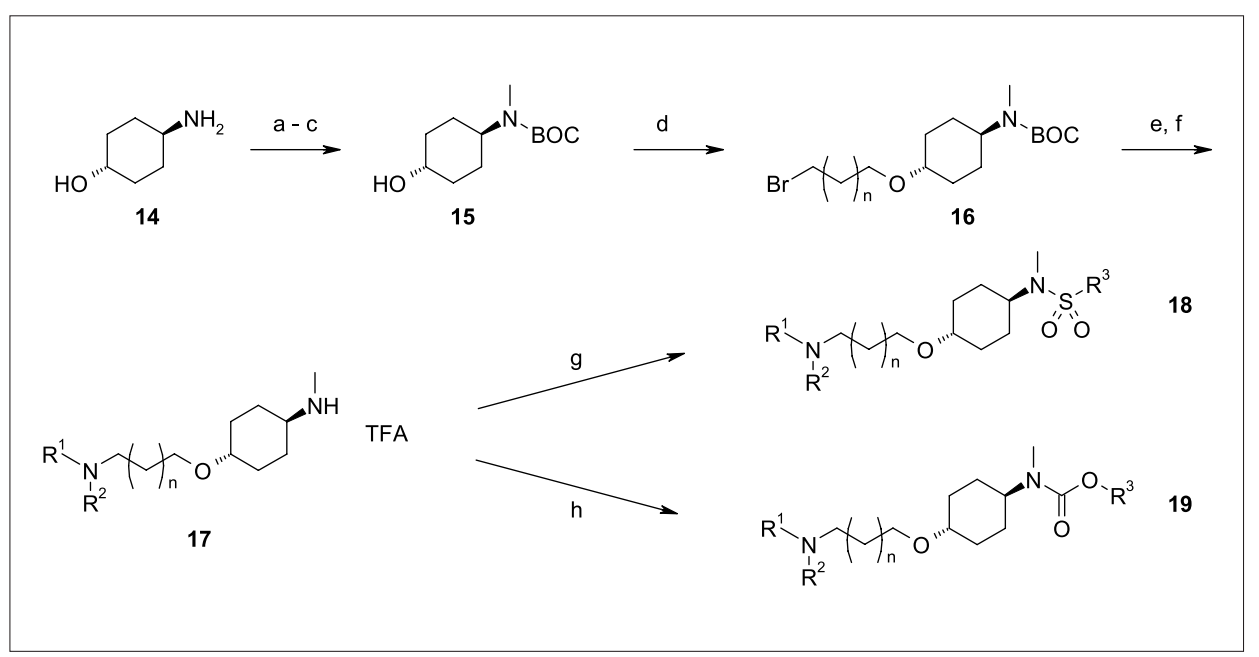

Scheme 2. Synthesis of aminocyclohexane derivatives with oxygen-linked spacers. Reagents and conditions: a) $\mathrm{ZCl}, \mathrm{Na}_{2} \mathrm{CO}_{3}, \mathrm{THF}, \mathrm{H}_{2} \mathrm{O}, \mathrm{rt}, 98 \%$; b) $\mathrm{LAH}, \mathrm{THF}, 0{ }^{\circ} \mathrm{C}$ to $\mathrm{rt}, 80 \%$; c) (BOC) ${ }_{2} \mathrm{O}, \mathrm{PrOH}$, $\mathrm{CH}_{2} \mathrm{Cl}_{2}, \mathrm{rt}, 98 \%$; d) $\alpha, \omega$-dibromoalkane, $\mathrm{Bu}_{4} \mathrm{NHSO}_{4}, \mathrm{NaOH}, \mathrm{H}_{2} \mathrm{O}, \mathrm{rt}, 76 \%$; e) $\mathrm{NHR}^{1} \mathrm{R}^{2}$, DMA, rt, $92 \%$; f) TFA, $\mathrm{CH}_{2} \mathrm{Cl}_{2}$, rt, $91 \%$; g) $\mathrm{R}^{3} \mathrm{SO}_{2} \mathrm{Cl}, i \mathrm{Pr}_{2} \mathrm{NEt} \mathrm{CH}_{2} \mathrm{Cl}_{2}$, rt, 50-80\%; h) $\mathrm{R}^{3} \mathrm{OCOCl}, i \mathrm{Pr}_{2} \mathrm{NEt}, \mathrm{CH}_{2} \mathrm{Cl}_{2}$, rt, $60-75 \%$.

of the ester to the aldehyde $\mathbf{2 1}$ could be achieved in a single step with DIBAL-H or alternatively, via $\mathrm{LiBH}_{4}$ reduction to the alcohol and re-oxidation using Swern conditions. Horner-Wadsworth-Emmons (HWE) reaction of $\mathbf{2 1}$ with triethyl phosphono acetate yielded the unsaturated ester 22. A second chain elongation of 22 to ester 23 was accomplished analogously. After hydrogenation of the double bond again a reduction/oxidation sequence and subsequent HWE reaction gave the desired ester 23. Hydrogenation of the double bond and LAH reduction followed by mesylation of the alcohol and cleavage of the BOC-protecting group using standard conditions yielded the building block $\mathbf{2 4}$ as TFA salt. Different sulfonamides $\mathbf{2 5}$ or carbamates $\mathbf{2 6}$ were prepared by reaction of $\mathbf{2 4}$ with sulfonyl chlorides or chloroformates, respectively, followed by treatment with primary or secondary amines. Again in a similar manner urea, sulfonamide, amide, thiourea or thioamide analogues have been prepared (not shown).

\section{Results and Discussion}

The compounds were tested first for the inhibition of $h \mathrm{OSC}$ at a single concentration $(100 \mathrm{nM})$. The potency of compounds from<smiles>CCOC(=O)C=CC1CCC(N(C)C(=O)OC(C)(C)C)CC1C=CC(=O)OCC</smiles><smiles>CNC1CCC(CCCCCOC)CC1</smiles>

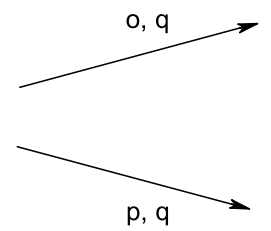<smiles>[R]OC(=O)N(C)C1CCC(CCCCCN([R])[R])CC1</smiles>

Scheme 3. Synthesis of aminocyclohexane derivatives with carbon-linked spacers. Reagents and conditions: a) Carbonyldiimidazol, $\mathrm{MeOH}$, rt, $99 \%$; b) $\mathrm{NaH}, \mathrm{Mel}$, DMF, $0^{\circ} \mathrm{C}$ to rt; c) $\mathrm{LiBH}_{4}$, THF, reflux; d) Oxalylchloride, DMSO, $\mathrm{NEt}_{3}, \mathrm{CH}_{2} \mathrm{Cl}_{2},-78^{\circ} \mathrm{C}$ to rt; e) triethyl-phosphono acetate, EtOH, $\mathrm{NaOMe}$, rt, 56\% (4 steps); f) Pd/C, $\mathrm{H}_{2}, \mathrm{MeOH}$, rt; g) $\mathrm{LiBH}_{4}$, THF, reflux, 73\% (2 steps); h) Oxalylchloride, $\mathrm{DMSO}, \mathrm{NEt}_{3}, \mathrm{CH}_{2} \mathrm{Cl}_{2},-78{ }^{\circ} \mathrm{C}$ to rt; i) triethyl-phosphono acetate, EtOH, NaOMe, rt, 58\% (2 steps); k) Pd/C, $\mathrm{H}_{2}, \mathrm{MeOH}$, rt; l) LAH, THF, rt, 97\%; m) $\left.\mathrm{MeSO}_{2} \mathrm{Cl}_{1} \mathrm{NEt}_{3}, \mathrm{CH}_{2} \mathrm{Cl}_{2}, \mathrm{rt} ; \mathrm{n}\right) \mathrm{TFA}, \mathrm{CH}_{2} \mathrm{Cl}_{2}, \mathrm{rt}, 73 \%$ (2 steps); o) $\mathrm{R}^{3} \mathrm{SO}_{2} \mathrm{Cl}, i \mathrm{Pr}_{2} \mathrm{NEt}$, dioxane, rt, 55-76\%; p) $\mathrm{R}^{3} \mathrm{OCOCl}$, $i \mathrm{Pr}_{2} \mathrm{NEt}$, dioxane, rt, 70-85\%; q) $\mathrm{NHR}^{1} \mathrm{R}^{2}$, DMA, rt, $60-75 \%$. 


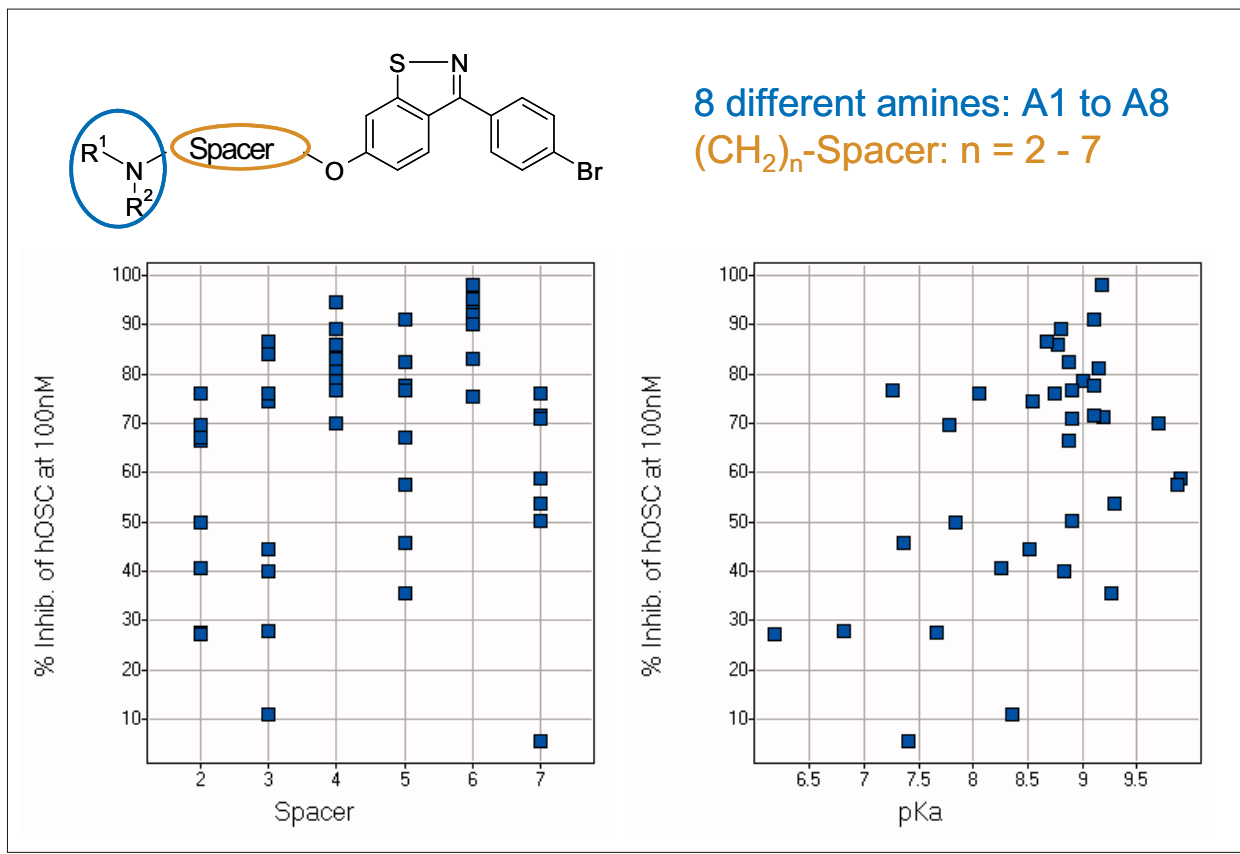

Fig. 2. Potency of benzo[d]isothiazole derivatives

Table 1. In vitro activities of selected compounds from the two series

\begin{tabular}{|c|c|c|c|c|c|c|c|}
\hline \multirow[b]{2}{*}{ Cpd } & \multirow[b]{2}{*}{$\mathbf{R}^{1}$} & \multirow[b]{2}{*}{$R^{2}$} & \multirow[b]{2}{*}{$\mathbf{n}$} & \multirow[b]{2}{*}{$\mathbf{R}^{3}$} & \multirow{2}{*}{$\begin{array}{c}\text { Inhibition of } \\
\text { hOSC } \\
I_{\mathrm{IC}_{50} \mathrm{a}} \\
{[\mathrm{nM}]}\end{array}$} & \multicolumn{2}{|c|}{$\begin{array}{l}\text { Residual inhibitory } \\
\text { activity after incubation } \\
\text { with rat hepatocytes }\end{array}$} \\
\hline & & & & & & $2 \mathrm{~h}$ & $24 h$ \\
\hline 1 & & & & & 6 & $93 \%$ & $42 \%$ \\
\hline $9 a$ & $\mathrm{Me}$ & allyl & 4 & & 3 & $97 \%$ & $87 \%$ \\
\hline $9 b$ & Et & $\mathrm{HOCH}_{2} \mathrm{CH}_{2}$ & 2 & & 18 & $97 \%$ & $74 \%$ \\
\hline $11 a$ & $\mathrm{Me}$ & allyl & 4 & & 7.8 & $94 \%^{d}$ & $93 \% d$ \\
\hline $13 a$ & $\mathrm{Me}$ & allyl & 4 & & $5 \%^{b}$ & n.d. & n.d. \\
\hline $18 a$ & Et & $\mathrm{MeOCH}_{2} \mathrm{CH}_{2}$ & 1 & $\mathrm{Ph}-p \mathrm{CF}_{3}$ & 17 & $94 \%$ & $77 \%$ \\
\hline $19 a$ & $\mathrm{Et}$ & $\mathrm{HOCH}_{2} \mathrm{CH}_{2}$ & 1 & $\mathrm{Ph}-\mathrm{pCl}$ & 45 & $91 \%$ & $79 \%$ \\
\hline $19 b$ & $\mathrm{Me}$ & allyl & 2 & $\mathrm{Ph}-p \mathrm{CF}_{3}$ & 25 & $95 \%$ & $25 \%$ \\
\hline $25 a$ & Et & $\mathrm{HOCH}_{2} \mathrm{CH}_{2}$ & & $\mathrm{Ph}-p \mathrm{CF}_{3}$ & 11 & $98 \%$ & $90 \%$ \\
\hline $26 a$ & $\mathrm{Me}$ & allyl & & $\mathrm{Ph}-p \mathrm{CF}_{3}$ & 5 & $99 \%$ & $86 \%$ \\
\hline
\end{tabular}

Table 2. In vivo activities of selected compounds

$\begin{array}{ccccc}\text { Cpd } & \begin{array}{c}\text { dose } \\ {[\mathrm{mg} / \mathrm{kg} / \mathrm{d}]}\end{array} & \begin{array}{c}\text { TC } \\ {[\%]}\end{array} & \begin{array}{c}\text { LDL-C } \\ {[\%]}\end{array} & \begin{array}{c}\text { TG } \\ {[\%]}\end{array} \\ \mathbf{1} & 100 & -30 & -49 & -19 \\ \mathbf{2 5 a} & 3 & -26 & -30 & -15 \\ \mathbf{2 6 a} & 6 & -23 & -26 & -28\end{array}$

TC, LDL-C and TG lowering in fat-fed hamsters is expressed as a percent of day 0 (before compound administration) and corrected with respect to the variation of the untreated group. the benzo[d]isothiazole series for derivatives with various $\mathrm{CH}_{2}$-spacer lengths and eight different amines is depicted in Fig. 2. Potent compounds can be identified with all the different spacer lengths tested, but there seems to be a slight preference for the butyl and the hexyl spacer. With these two chain lengths very active compounds were found for all of the eight amines tested. Furthermore, the basicity of the amine for compounds can range from $\mathrm{pKa}$ values of 6.0 to 10 , but a $\mathrm{pKa}$ value between $7.8-9.5$ seems to be preferred [25]. Further evaluation of different amine residues in this series then focused on the butyl spacers.

Those compounds that showed an inhibition of $>50 \%$ at $100 \mathrm{nM}$ were evaluated in rat hepatocytes. In this assay both the cellular activity and the metabolic stability of the compounds could be assessed. The test allowed measurement of the potency of each test substance in reducing cholesterol production. At the same time the metabolic stability (residual activity) could be determined by comparing the reduction of cholesterol production after pre-incubation of the cells for $24 \mathrm{~h}$ with that of co-incubation of only $2 \mathrm{~h}$ [17]. Data for representative derivatives from both series are depicted in Table 1. Replacing the benzophenone by a phenyl-substituted benzo[d]isothiazole is tolerated as can seen by comparing the potency of compounds 1 and 9a. Both 9a and $\mathbf{9 b}$ exhibited higher stability as compared to the starting benzophenone 1 . The dioxo-benzo[d]isothiazole 11a was slightly less potent than the benzo[d]isothiazole 9a but showed similar metabolic stability in the hepatocyte assay. For substituted benzo[d]isothiazole 13a the activity was reduced significantly.

In the aminocyclohexane series several potent inhibitors were identified. In the ether linked subseries sulfonamide 18a and carbamates 19a showed similar stability to the benzo[d]isothiazole $\mathbf{9 b}$ whereas the carbamate 19b was less stable. With the corresponding carbon analogue of $\mathbf{1 9 b}$, the carbamate 26a, this property is significantly improved. A high metabolic stability was also observed for the sulfonamide 25a.

The most promising compounds from these new series were evaluated for their ability to modify lipid parameters in vivo. For that purpose compounds were given to hyperlipidemic hamsters as food admix for 14 days and levels of plasma total cholesterol (TC), LDL-C and TG were measured and compared to the control group. Data for two selected aminocyclohexane derivatives, 25a and 26a, are depicted in Table 2 in comparison to $\mathbf{1}$. The compounds showed a significant reduction in all three parameters, although dosed significantly lower 
than 1. As the compounds show similar in vitro potency this might be attributed to the improvement of the metabolic stability as determined in the rat hepatocyte assay.

\section{Conclusion}

Starting from 1 (Ro 48-8071), different new chemical scaffolds as replacement for the benzophenone moiety were evaluated. The individual series could be explored rapidly by the use of parallel chemistry as shown for two representative series, leading to the identification of phenyl-substituted benzo[d]isothiazole and aminocyclohexane class which showed improved stability (residual activity) in rat hepatocytes. The most promising compounds $\mathbf{2 5 a}$ and 26a from the aminocyclohexane series showed efficient lowering of plasma TC, LDL-C, and TG levels in hyperlipidemic hamsters and were selected for further profiling.

\section{Acknowledgments}

We sincerely thank Daniel Egger, Gisela Flach, Felix Gruber, Corinne Handschin, Dorian Heinrich, Barbara Huber, Marie-Paule Imhoff, Ann Kaiser, Isabelle Kaufmann, Hans-Jakob Krebs, Anke Kurt, Heidi Stoll and Björn Wagner for their excellent and dedicated work.

Received: January 6, 2005

[1] http://www.americanheart.org/ downloadable/heart/ 1077185395308FS06INT4(ebook).pdf

[2] ATP III Final Report, Circulation 2002, 106, 3143 .

[3] R.L. Talbert, Am. J. Manag. Care 2002, 8, S301.

[4] E. Bruckert, Expert Opin. Investig. Drugs 2003, 12, 325.

[5] M.B. Clearfield, Expert Opin. Pharmacother. 2002, 3, 469
[6] G. Assmann, P. Cullen, H. Schulte, Eur. Heart J. 1998, 19 Suppl A, A2.

[7] A.M. Gotto, Jr., Am. J. Med. 2002, 112, $10 \mathrm{~S}$.

[8] P.W. Wilson, Am. J. Hypertens. 1994, 7, $7 \mathrm{~S}$.

[9] O.H. Morand, J.D. Aebi, H. Dehmlow, Y.H. Ji, N. Gains, H. Lengsfeld, J. Himber, J. Lipid Res. 1997, 38, 373.

[10] E.J. Corey, S.C. Virgil, H. Cheng, C.H. Baker, S.P.T. Matsuda, V. Singh, S. Sarshar, J. Am. Chem. Soc. 1995, 117, 11819.

[11] T. Schulz-Gasch, M. Stahl, J. Comp. Chem. 2003, 24, 741.

[12] D.M. Peffley, A.K. Gayen, O.H. Morand, Biochem. Pharmacol. 1998, 56, 439.

[13] B.A. Janowski, M.J. Grogan, S.A. Jones, G.B. Wisely, S.A. Kliewer, E.J. Corey, D.J. Mangelsdorf, Proc. Natl. Acad. Sci. USA 1999, 96, 266.

[14] K.A.R. Tobin, H.H. Steineger, S. Alberti, O. Spydevold, J. Auwerx, J.-A. Gustafsson, H.I. Nebb, Mol. Endocrinology 2000, 14, 741 .

[15] S. Jolidon, A. Polak-Wyss, P.G. Hartman, P. Guerry, in 'Molecular Aspects of Chemotherapy', Eds. D. Shugar, W. Rode, E. Borowski, Polish Scientific Publishers PWN, Warszawa, 1991, pp. 143.

[16] S. Jolidon, A. Polak-Wyss, P.G. Hartman, P. Guerry, in 'Recent Advances in the Chemistry of Anti-infective Agents', Eds. P. H. Bentley, R. Ponsford, Royal Soc. Chem., Cambridge, 1993, pp. 223.

[17] H. Dehmlow, J.D. Aebi, S. Jolidon, Y.-H. Ji, E.M. Von Mark, J. Himber, O.H. Morand, J. Med. Chem. 2003, 46, 3354.

[18] R. Thoma, T. Schulz-Gasch, B. D’Arcy, J. Benz, J. Aebi, H. Dehmlow, M. Hennig, M. Stihle, A. Ruf, Nature 2004, 432, 118.

[19] K.U. Wendt, A. Lenhart, G.E. Schulz, J. Mol. Biol. 1999, 286, 175.

[20] A. Lenhart, W.A. Weihofen, A.E.W. Pleschke, G.E. Schulz, Chem. Biol. 2002,
9, 639; A. Lenhart, D.J. Reinert, J.D. Aebi, H. Dehmlow, O.H. Morand, G.E. Schulz, J. Med. Chem. 2003, 46, 2083.

[21] D. Robinson, R. T. Williams, Biochem. J. 1957, 66, 46P.

[22] J. Aebi, J. Ackermann, H. Dehmlow, H.-P. Maerki, O. Morand, (F. HoffmannLa Roche AG), PCT Int. Appl. 2002, WO2002036584; J. Ackermann, J. Aebi, H. Dehmlow, O. Morand, N. Panday, T. Weller, (F. Hoffmann-La Roche AG), PCT Int. Appl. 2002, WO2002044149; J. Aebi, J. Ackermann, A. Chucholowski, H. Dehmlow, O. Morand, S. Wallbaum, T. Weller, N. Panday, (F. Hoffmann-La Roche AG), PCT Int. Appl. 2002, WO2002050041; J. Ackermann, J. Aebi, A. Chucholowski, H. Dehmlow, O. Morand, S. Wallbaum, T. Weller, (F. Hoffmann-La Roche AG), PCT Int. Appl. 2002, WO 2002020483; J. Ackermann, J. Aebi, D. Blum, A. Chucholowski, H. Dehmlow, H.-P. Maerki, O. Morand, R. Trussardi, E. Von der Mark, S. Wallbaum, T. Weller, (F. Hoffmann-La Roche AG), PCT Int. Appl. 2002, WO 2002014267; J. Ackermann, J. Aebi, A. Chucholowski, H. Dehmlow, O. Morand, S. Wallbaum, T. Weller, (F. Hoffmann-La Roche AG), PCT Int. Appl. 2002, WO 2002006189; J. Ackermann, J. Aebi, H. Dehmlow, G. Hirth, H.-P. Maerki, O. Morand, (F. Hoffmann-La Roche AG), PCT Int. Appl. 2003, WO2003053919.

[23] D.M. Fink, J.T. Strupczewski, Tetrahedron Lett. 1993, 34, 6525.

[24] A.M. Belostotskii, A. Hassner, Tetrahedron Lett. 1994, 35, 5075.

[25] pKa measurements were performed using a method described by B.A. Hendriksen, M.V. Sanchez-Felix, K.Y. Tam, Spectroscopy Letters 2002, 35, 9. 